\title{
Vezikoüreteral Reflüde Endoskopik Enjeksiyon Tedavisi - Kime? Nereye? Ne Kadar?
}

\author{
M. İrfan Dönmez, Tayfun Oktar
}

İstanbul Üniversitesi, İstanbul Tıp Fakültesi, Üroloji Anabilim Dalı, Çocuk Ürolojisi Bilim Dalı, 34390 - Çapa, İstanbul

$\mathrm{V}$ ezikoüreteral reflü (VUR) çocuklarda \%1 insidansa sahip olan ve özelikle uzun vadede renal skar, hipertansiyon ve kronik böbrek yetmezliğine sebep olabilen bir hastalıktır (1). Tedavide amaç böbrek fonksiyonunu korumak ve gelişebilecek olan piyelonefrit ataklarını engellemektir. Son 2 dekatta endoskopik enjeksiyon yöntemi bu hastalığın tedavisinde daha az invaziv bir metod olarak ortaya konmuştur. $\mathrm{Bu}$ yöntemle birlikte hastanede yatışa gerek olmadan yapılabilen bir işlemle vezikoüreteral reflünün tedavi edilmesi mümkün olmuştur. Bu yazıda bu yöntemin hangi hastalar için uygun olduğu işlemin teknik detayları ile irdelenecektir.

Literatürde yaygın bilinen ismiyle STING (Subureteric Transurethral Injection) işlemi ilk olarak 1981 yılında Matouschek tarafından tanımlanmış olup O'Donnell ve Puri tarafından popülarize edilmiştir $(2,3)$. STING metodunda amaç subüreterik bir lokalizasyondan üreterin submukozal kısmına bahsi geçen enjeksiyon maddelerinin yerleştirilmesi ilkesine dayanır. Bu sayede üreterin intramural kısmının uzaması, lümenin daralması ve koaptasyonunun artması amaçlanmaktadır. Enjeksiyonun gereğinden derine yapılması başarıyı olumsuz etkilemekte ve materyalin Waldeyer kılıfı boyunca dağılmasına sebep olmaktadır. Özellikle yüksek basınçlı mesanelerde enjeksiyon materyalinin zamanla medial ve distale doğru yer değiştirdiği gözlenmiştir (4).

Enjeksiyon için tarihsel süreç içinde birçok farklı molekül kullanılmıştır. Optimal molekülün doğada inert, ucuz, enjekte edilebilecek kadar yumuşak ancak dolgu yapacak kadar vizköz olması, minimum doku reaksiyonu yapması ve karsinojenik olmaması beklenmektedir (5). Politetrafloroetilen (PTFE/Teflon), kollajen, otolog yağ, polidimetilsiloksan, silikon, kondrosit ve son olarak bir dekstranomer/hyaluronik asit solüsyonu olan Deflux ${ }^{\circledR}$ ile yapılmış çok çeşitli çalışmalarda farklı sonuçlar mevcuttur (6). Her ne kadar literatürde en başarılı sonuçlar PTFE ile ortaya konmuşsa da; partikül çapının $<40 \mu \mathrm{m}$ olması sebebiyle migrasyon (bölgesel lenf nodları, akciğer ve santral sinir sistemi) riski mevcuttur ve Amerika'da çocuklarda kullanım için onay alamamıştır. Dekstranomer/hyaluronik asit migrasyona ve hacmen redüksiyona uğramaması, biyo-uyumlu olması ve yapılan çalışmalarda tedavi başarısının yüksek bulunması sebebiyle optimal enjeksiyon materyaline en fazla yaklaşan moleküldür. $\mathrm{Bu}$ sebeplerden ötürü günümüzde kullanımı neredeyse standart hale gelmiştir (7).

Vezikoüreteral reflü tedavisinde cerrahi yöntemlere bir alternatif olan endoskopik enjeksiyon işleminin endikasyon- ları açık cerrahi ile benzerdir. EAU kılavuzlarına göre yüksek riskli olan hasta grubu tuvalet eğitimi almış, yüksek dereceli (4-5. Derece) reflüsü olan ve alt üriner sistem bozukluğu olan/olmayan skarlı böbreklere sahip semptomatik çocuklardır ve bu hastalarda ilk tercih olarak açık cerrahi yöntemleri öne çıkarılmaktadır (8). Bu hastalar dışında tüm gruplara endoskopik tedavi uygulanabilir. Endoskopik enjeksiyon tedavisine ait 5527 hasta ve 8101 renal ünitenin incelendiği bir meta-analizde, tek enjeksiyon ile grade 1 ve 2 reflülerde başarı \%78,5 bulunmuş olup bu oranlar grade 3,4 ve 5 reflülerde sırasıyla $\% 72, \% 63$ ve $\% 51$ olarak saptanmıştır. İlk enjeksiyon başarısız olduğunda ise; ikinci enjeksiyonun ortalama başarısı \%68 iken 3. enjeksiyonun başarısı yalnızca \%34'tür. Sonuç olarak bir veya daha fazla enjeksiyonla ortalama başarı \%85 olarak ortaya konmuştur (6). Eğer hastada alt üriner sistem bozukluğu (öz. işeme disfonksiyonu) mevcut ise öncelikle bu durumun tedavi edilmesi gereklidir aksi takdirde enjeksiyon işleminin başarısı düşecektir.

Subüreterik enjeksiyonun başarısının düşük olduğu diğer birkaç istisna ise duplike sistemler ve nöropatik mesanedir. Duplike sistemlerde iki orifise ayrı ayrı yapılabildiği gibi eğer orifisler çok yakınsa tek bir enjeksiyon da yeterli olabilmektedir Yapılan meta-analizde duplike sistemlerde enjeksiyon tedavisinin başarısı \%63 - 73 arasında değişmekte olduğu bulunmuştur. Elder ve ark. ise yaptıkları gözden geçirme çalışmasında nöropatik mesane olgularında başarı oranını yaklaşık \%53,5 olarak vermektedir (6). Ayrıca üreter reimplantasyonu yapılmış ancak başarısız olmuş olgularda endoskopik enjeksiyon işlemi denenebilir. Bu işlem neoüre-

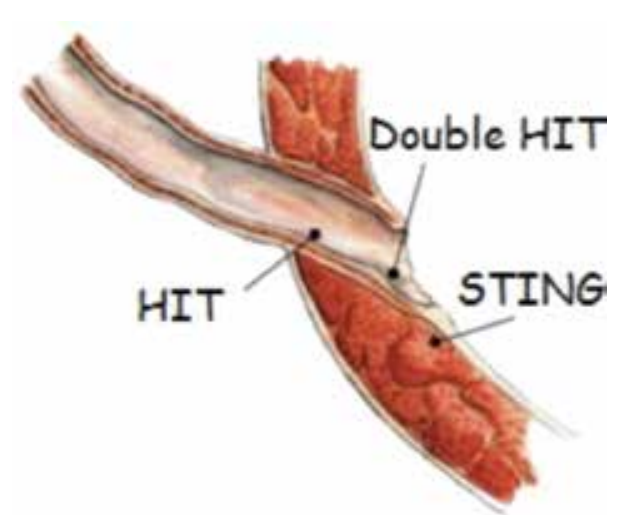

Resim 1: Metodlara göre enjeksiyon yerleri 

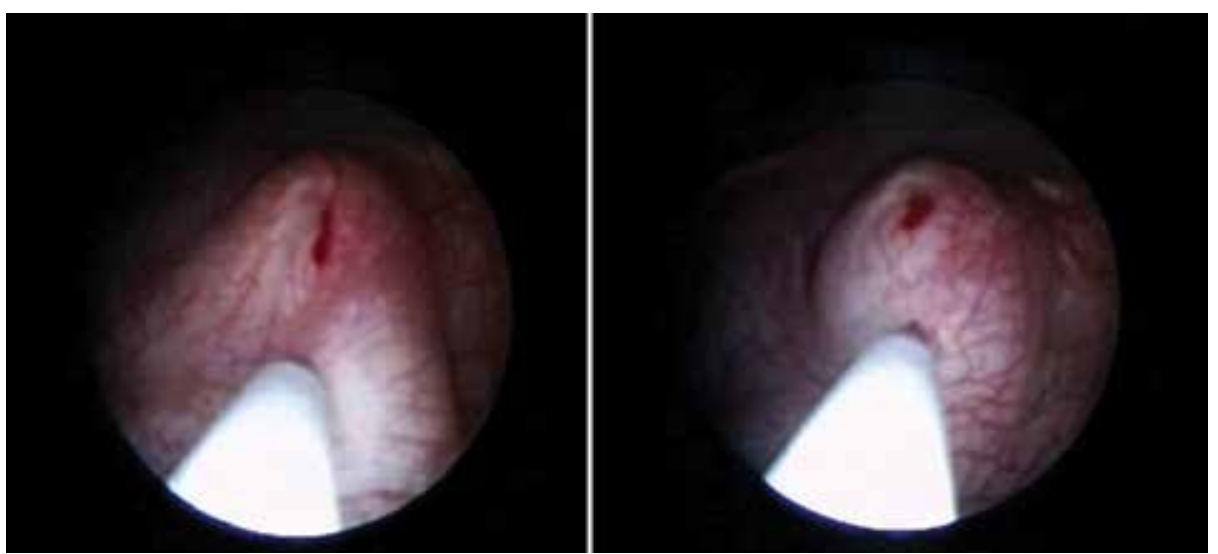

Resim 2: STING işlemi görüntüsü (IÜ İstanbul Tıp Fakültesi Üroloji ABD arşivinden alınmıştır.)

ter orifisinin lokalizasyonuna bağlı olarak zorlayıcı olabilir. Perez-Brayfield ve ark. bu tür olgularda \%88'lik bir başarı oranı bildirmiş olmasına karşın Elder ve ark. yaptıkları metaanalizde kümülatif başarıyı \%65 olarak bulmuşlardır $(6,9)$.

Başarısızlıkla sonuçlanan işlemleri sistoskopik olarak inceleyen yazılarda enjekte edilen materyalin distale ve mediale (mesane boynuna doğru) yer değiştirdiği bildirilmiştir. Endoskopik enjeksiyon yönteminin kontrendikasyonları arasında obstrüktif ve reflüksif megaüreter varlığı ile aktif idrar yolu enfeksiyonu sayılabilir.

İşlem için genellikle pediatrik sistoskopi sistemi yeterlidir. Sistoskopun çalışma kanalından plastik veya metal gövdeli 3 - 5 F kalınlığındaki enjeksiyon iğnelerinin rahatlıkla geçmesi gereklidir. Teknik klasik olarak litotomi pozisyonundaki hastaya yapılan sistoüretroskopi ile başlar, her hastada işlem öncesinde üretra ve mesane olası ek anomaliler açısından dikkatlice değerlendirilmelidir. Üreter orifislerinin yeri, konfigürasyonu ve sayısı takip amaçlı not edilmelidir (10). Klasik STING tekniği O’Donnell ve Puri tarafından saat 6 hizasından iğnenin ağzı yukarıya bakacak şekilde üreteral orifisin 2-3 mm altından iğnenin intravezikal üreter içine submukozal olarak $0,5 \mathrm{~cm}$ ilerletilmesi ve yavaş enjeksiyon yapılarak volkan görünümünün oluşturulması şeklinde tanımlanmıştır. Bu görüntü oluştuğunda sistoskopun yıkama kanalından gönderilen irrigasyon sıvısının üreter orifisinden yukarıya gitmediğini görmek önemli bir ayrıntıdır. Eğer tekniğe uygun yapılırsa 0,3 - 0,7 cc enjeksiyon materyali yeterli olacaktır. Yüksek dereceli reflülerde Puri modifiye bir teknik olarak üreter içerisine saat 6 hizasından enjeksiyonu tanımlamıştır (11). Hidrodistansiyon enjeksiyon yönteminde (HIT) ise öncelikle üreter orifisine irrigasyon sıvısının gönderilmesiyle submukozal enjeksiyon için en uygun yer aranır. İgne yine saat 6 hizasından intramural üreterin orta kısmina kadar gönderilir ve submukozal olarak $4 \mathrm{~mm}$ kadar ilerletilir. Minimal materyal enjekte edilerek iğnenin doğru yerde olup olmadığı kontrol edilir. Doğru yerde olunduğundan emin olunduktan sonra sıvı irrigasyonuna ara verilir ve kalan materyal enjekte edilmeye devam edilir (12). Uygun volkan veya yarımay görüntüsü oluşana kadar enjeksiyon materyali verilebilir. Verilecek materyal gerekli volkan görüntüsünü yapmaya yetecek kadar olmalıdır. Eğer gerekenden fazla materyal verilmesine rağmen volkan görüntüsü oluşmuyorsa mutlaka iğnenin yeri kontrol edilmelidir. İşlem bitiminde iğne yavaşça geri çekilirken enjeksiyona devam edilerek tüm distal üreter boyunca koaptasyon sağlanmaya çalışılır. İ̆gnenin işlem bitiminde hemen çıkartılmaması ve yaklaşık 0,5 - $1 \mathrm{dk}$ beklenmesi bazı uygulayıcılar tarafından önerilmektedir. Double HIT metodunda ise üreter orifisinin hemen girişinden ikinci bir enjeksiyon yapılarak başarı artırılabilmeye çalışılmaktadır. HIT yöntemiyle yeterli koaptasyon sağlanamazsa klasik STING metodu ile ikinci bir enjeksiyon yapılması gerekebilir. Elbette bu yöntem için daha fazla enjeksiyon materyali gereklidir ( 1,5 cc). Literatürde skarlı böbreklerde gösterilemeyen reflü olgularında PIC (Positional Instillation of Contrast) metodu kullanılarak okkült reflülerin saptanabileceği belirtilmiştir. Tartışmalı olan bu yöntemde sistoskopun ucu şüpheli üreter ofisine doğru tutulur, $1 \mathrm{~m}$ yukarıya asılmış olan kontrast madde üreter orifisine doğru serbest akımla yönlendirilir ve floroskopi yardımıyla reflü olup olmadığı saptanmaya çalışılır (13).

Sonuç olarak endoskopik enjeksiyon yöntemi vezikoüreteral reflü tedavisini minimal invaziv bir hale getirmiş ve böylelikle çok daha yaygın olarak ve kolaylıkla yapılmasını sağlamıştır. Elbette bu yöntemin başarısı uygun teknik kullanılmadığı takdirde düşmektedir. İşlemden sonra kontrol işeme sistoüretrografisi çekilmek suretiyle başarı değerlendirilmeli ve özellikle ikinci enjeksiyondan da klinik/radyolojik fayda görmeyen hastalarda açık cerrahi denenmelidir.

\section{Kaynaklar}

1. Blumenthal I: Vesicoureteric reflux and urinary tract infection in children. Postgraduate medical journal 2006, 82(963):31-35.

2. Matouschek E: [New concept for the treatment of vesico-ureteral reflux. Endoscopic application of teflon]. Archivos espanoles de urologia 1981, 34(5):385-388.

3. O'Donnell B, Puri P: Treatment of vesicoureteric reflux by endoscopic injection of Teflon. British medical journal 1984, 289(6436):7-9.

4. Capozza N, Caione P, De Gennaro M, Nappo S, Patricolo $\mathrm{M}$ : Endoscopic treatment of vesico-ureteric reflux and urinary incontinence: technical problems in the paediatric patient. British journal of urology 1995, 75(4):538-542.

5. Sugiyama T, Hanai T, Hashimoto K, Umekawa T, Kurita $\mathrm{T}$ : Long-term outcome of the endoscopic correction of vesico-ureteric reflux: a comparison of injected substances. BJU international 2004, 94(3):381-383. 
6. Elder JS, Diaz M, Caldamone AA, Cendron M, Greenfield S, Hurwitz R, Kirsch A, Koyle MA, Pope J, Shapiro E: Endoscopic therapy for vesicoureteral reflux: a metaanalysis. I. Reflux resolution and urinary tract infection. The Journal of urology 2006, 175(2):716-722.

7. Elmore JM, Scherz HC, Kirsch AJ: Dextranomer/ hyaluronic acid for vesicoureteral reflux: success rates after initial treatment failure. The Journal of urology 2006, 175(2):712-715.

8. Tekgul S, Riedmiller H, Hoebeke P, Kocvara R, Nijman RJ, Radmayr C, Stein R, Dogan HS, European Association of $\mathrm{U}$ : EAU guidelines on vesicoureteral reflux in children. European urology 2012, 62(3):534-542.

9. Perez-Brayfield M, Kirsch AJ, Hensle TW, Koyle MA, Furness P, Scherz HC: Endoscopic treatment with dextranomer/hyaluronic acid for complex cases of vesicoureteral reflux. The Journal of urology 2004, 172(4 Pt 2):1614-1616.

10. Lyon RP, Marshall S, Tanagho EA: The ureteral orifice: its configuration and competency. The Journal of urology 1969, 102(4):504-509.
11. Chertin B, De Caluwe D, Puri P: Endoscopic treatment of primary grades IV and V vesicoureteral reflux in children with subureteral injection of polytetrafluoroethylene. The Journal of urology 2003, 169(5):1847-1849; discussion 1849.

12. Kirsch AJ, Perez-Brayfield M, Smith EA, Scherz HC: The modified sting procedure to correct vesicoureteral reflux: improved results with submucosal implantation within the intramural ureter. The Journal of urology 2004, 171(6 Pt 1):2413-2416.

13. Rubenstein JN, Maizels M, Kim SC, Houston JT: The PIC cystogram: a novel approach to identify "occult" vesicoureteral reflux in children with febrile urinary tract infections. The Journal of urology 2003, 169(6):2339-2343.

Yazışma Adresi:

Tayfun Oktar

İstanbul Üniversitesi, İstanbul Tıp Fakültesi,

Üroloji Anabilim Dall, 34390 - Çapa, İstanbul

Tel: +90 2124142000 / 32640

e-mail: tayfunoktar@hotmail.com 